\title{
Characterization of esophageal motor
} activity, gastroesophageal reflux, and evaluation of prokinetic effectiveness in mechanically ventilated critically ill patients: a high-resolution impedance manometry study

\author{
Karel Balihar®, Jan Kotyza, Lucie Zdrhova, Jana Kozeluhova, Michal Krcma® and Martin Matejovic ${ }^{*}$ (i)
}

\begin{abstract}
Background: Motility disorders of upper gastrointestinal tract are common in critical illness and associated with significant clinical consequences. However, detailed quantitative and qualitative analyses of esophageal motor functions are lacking. Therefore, we aimed to characterize the key features of esophageal motility functions using high-resolution impedance manometry (HRIM) and to evaluate an objective link between esophageal motor patterns, gastric emptying, and gastroesophageal reflux. We also studied the prokinetic effects of metoclopramide.

Methods: We prospectively performed HRIM for 16 critically ill hemodynamically stable patients. Patients were included if they had low gastric volume $(\mathrm{LGV} ;<100 \mathrm{~mL} / 24 \mathrm{~h}, n=8)$ or high gastric volume $\left(\mathrm{HGV}_{i}>500 \mathrm{~mL} / 24 \mathrm{~h}\right.$, $n=8)$. The HRIM data were collected for $5 \mathrm{~h}$ with intravenous metoclopramide administration $(10 \mathrm{mg})$ after the first $2 \mathrm{~h}$.

Results: The findings were grossly abnormal for all critically ill patients. The esophageal contraction vigor was markedly increased, indicating prevailing hypercontractile esophagus. Ineffective propulsive force was observed for 73\% of esophageal activities. Panesophageal pressurization was the most common pressurization pattern (64\%). Gastroesophageal reflux predominantly occurred with transient lower esophageal sphincter relaxation. The common features of the LGV group were a hyperreactive pattern, esophagogastric outflow obstruction, and frequent reflux. Ineffective motility with reduced lower esophageal sphincter tone, and paradoxically fewer reflux episodes, was common in the HGV group. Metoclopramide administration reduced the number of esophageal activities but did not affect the number of reflux episodes in either group.

Conclusion: All critically ill patients had major esophageal motility abnormalities, and motility patterns varied according to gastric emptying status. Well-preserved gastric emptying and maintained esophagogastric barrier functions did not eliminate reflux. Metoclopramide failed to reduce the number of reflux episodes regardless of gastric emptying status.
\end{abstract}

*Correspondence: matejovic@fnplzen.cz

Department of Internal Medicine, Faculty of Medicine in Pilsen,

Pilsen University Hospital, Charles University Prague, Alej Svobody 80,

30406 Pilsen, Czech Republic

(c) The Author(s) 2021. Open Access This article is licensed under a Creative Commons Attribution 4.0 International License, which permits use, sharing, adaptation, distribution and reproduction in any medium or format, as long as you give appropriate credit to the original author(s) and the source, provide a link to the Creative Commons licence, and indicate if changes were made. The images or other third party material in this article are included in the article's Creative Commons licence, unless indicated otherwise in a credit line to the material. If material is not included in the article's Creative Commons licence and your intended use is not permitted by statutory regulation or exceeds the permitted use, you will need to obtain permission directly from the copyright holder. To view a copy of this licence, visit http://creativecommons.org/licenses/by/4.0/. The Creative Commons Public Domain Dedication waiver (http://creativeco mmons.org/publicdomain/zero/1.0/) applies to the data made available in this article, unless otherwise stated in a credit line to the data. 
Trial registration ISRCTN, ISRCTN14399966. Registered 3.9.2020, retrospectively registered. https://www.isrctn.com/ ISRCTN14399966.

Keywords: Critical illness, Esophageal dysfunction, High-resolution impedance manometry, Prokinetics, Gastroesophageal reflux

\section{Introduction}

Dysfunction of the upper gastrointestinal tract (UGIT) leads to deterioration in the patient's nutritional status, bacterial colonization, and increased risks of reflux esophagitis, and aspiration [1]. Unfortunately, there is very little quantitative and qualitative data regarding esophageal motility functions in mechanically ventilated critically ill patients. Kölbel et al. performed a pilot study of 15 mechanically ventilated patients, which revealed that they had decreased propulsive esophageal motility that was further impaired by any kind of sedation [2]. Nind et al. also evaluated 15 mechanically ventilated patients and reported that gastroesophageal reflux was predominantly related to low or absent lower esophageal sphincter (LES) pressure, which often coexisted with cough or straining [3]. However, those studies evaluated esophageal motility using conventional manometry, where the sensors are spaced at 3-5-cm intervals.

Unlike conventional manometry, high-resolution impedance manometry (HRIM) measures esophageal pressures with 423 sensors distributed longitudinally and radially in the esophagus, along with esophageal impedance monitoring (18 sensors), thus allowing for a very detailed evaluations of esophageal pressures, peristalsis, sphincter functions, and reflux [4]. It might, therefore, identify relevant abnormalities not detected by conventional manometry. Among critically ill patients, pharyngeal HRIM has only recently been used in a study of post-extubation dysphagia [5]. Persson et al. used HRM to evaluate factors affecting esophageal pressures during changes in ventilator settings [6]. Ahlstrand et al. showed that muscle relaxation with rocuronium does not decrease the barrier pressure during anesthesia induction [7]. We believe that HRIM has great potential to improve our understanding of esophageal functions in critically ill patients. In particular, deeper insights into the complex relationships between esophageal motility patterns, antireflux barrier, and gastric emptying may pave way for more effective and safe treatment options and patient care. Therefore, the present mechanistic study used HRIM to characterize the features of esophageal motility in ventilated patients who were receiving intensive care, and evaluated the esophageal physiology and occurrence of reflux depending on the gastric nutritional tolerance. In addition, the effects of metoclopramide were evaluated and related to the esophageal motility patterns.

\section{Methods}

\section{Study design, population, and setting}

This prospective exploratory study evaluated adults ( $\geq 18$ years) who were admitted to the medical intensive care unit of a tertiary academic referral center. The study was conducted in accordance with Good Clinical Practice, as defined by the International Conference on Harmonization, the ethical principles underlying European Union Directive 2001/20/EC, and all applicable local requirements. The study protocol was approved by the appropriate institutional review board and ethics committee. Informed consent was obtained from the patients' next of kin, as well as the patients themselves once they had regained the capacity to provide informed consent.

Patients were considered eligible for the study if they were mechanically ventilated, hemodynamically stable (maximum stable dose of noradrenaline of $0.2 \mu \mathrm{g}$ / $\mathrm{kg} / \mathrm{min}$ ), and had initiated gastric enteral nutrition. The patients were subclassified based on their residual gastric volume (GRV) at $24 \mathrm{~h}$ before enrolment as having either low residual gastric volume (LGV; $\leq 100 \mathrm{~mL} / 24 \mathrm{~h}, n=8$ ) or high gastric volume (HGV; $\geq 500 \mathrm{~mL} / 24 \mathrm{~h}, n=8)$. Patients were excluded if they had GRV between 100 and $500 \mathrm{ml} / 24 \mathrm{~h}$, a history of surgery for UGIT dysfunction, gastroesophageal reflux disease, portal hypertension, or active bleeding in the UGIT.

All critically ill patients received the same caliber of nasogastric tube (16 Fr) and the head of the bed was elevated to $30^{\circ}$. All patients received anti-ulcer prophylaxis using histamine 2-type receptor blockers or proton pump inhibitors, as well as a standard enteral nutrition formula (Nutrison Energy, $1.5 \mathrm{kcal} / \mathrm{mL}$, Nutricia). Residual gastric volumes were assessed every $3 \mathrm{~h}$ via active suction. Sedation and/or analgesia were minimized in a goal-directed fashion and targeted light sedation (Richmond Agitation Sedation Score of -2 to 0 ), with only propofol and/or sufentanil used to ensure the patient's comfort. HRIM analysis included resting parameters of the esophagogastric junction (EGJ), dynamic parameters of all dry swallows, panesophageal secondary peristalsis, and analysis of reflux episodes according to the impedance measurements. A detailed description of the HRIM measurements for the critically ill patients is provided in Additional file 1. The study protocol scheme is shown in Fig. 1 and the monitored parameters are shown in Table 1. 


\section{Scheme of study protocol}

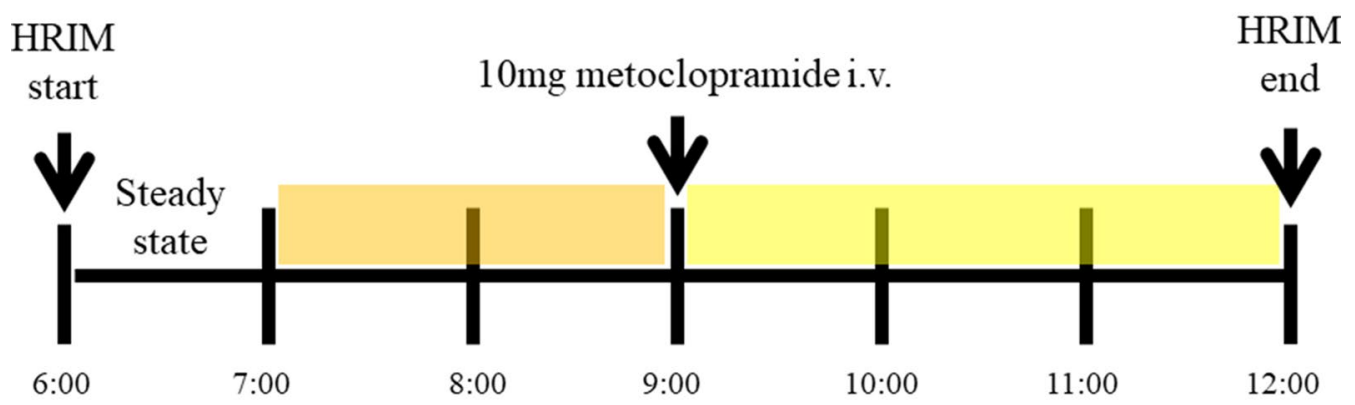

Fig. 1 Scheme of study protocol

HRIM - High resolution impedance manometry

Table 1 Variables monitored during HRIM study in critically ill patients

\begin{tabular}{|c|c|}
\hline Clinical parameters: & $\begin{array}{l}\text { Mean arterial pressure, heart rate, respiratory rate, oxygen saturation, body temperature (every hour), } \\
\text { intraabdominal pressure ( } 2 \times \text { during the study), ventilator setting }\end{array}$ \\
\hline Laboratory parameters: & Arterial lactate, hemoglobin, creatinine, bilirubin, albumin, CRP, INR at 5:00, glycemia at 6:00, 9:00, 12:00 \\
\hline HRM resting parameters & $\begin{array}{l}\text { Tonus of } \text { LES }^{\text {a }} \\
\text { Inspiratory EGJ pressure (EGJP-insp). Average maximal inspiratory EGJ pressure for three respiratory cycles }{ }^{a} \\
\text { Expiratory EGJ pressure (EGJP-exp). Average EGJ pressure midway between inspirations for the same three respiratory } \\
\quad \text { cycles }^{\text {a }} \\
\text { Esophagogastric junction contractile integral }(E G J-C I)^{a}\end{array}$ \\
\hline HRM dynamic parameters & $\begin{array}{l}\text { Number of dry swallows and panesophageal secondary peristalsis/1 h } \\
\text { Distal contractile integral (DCI) } \\
\% \text { of failed peristalsis } \\
\% \text { of panesophageal pressurizations } \\
\% \text { of premature contractions } \\
\% \text { of double-peaked waves } \\
\text { Integrated relaxation time (IRP) } \\
\text { Intrabolus pressure (IBP) }\end{array}$ \\
\hline Impedance & $\begin{array}{l}\text { Number of liquid, mixed, and gaseous reflux episodes (defined as a sequential oral progressive decrease/increase in imped- } \\
\text { ance below/above } 40 \% \text { baseline values distally with a retrograde propagation by at least } 2 \text { additional proximal observed } \\
\text { fields in the absence of explanatory peristaltic component (median/hour of study) } \\
\text { Number of distal and proximal refluxes } \\
\text { Origin mechanism for each reflux episode: } \\
\text { Swallow associated reflux (reflux within } 10 \text { s of finished swallow) } \\
\text { Panesophageal secondary peristalsis associated reflux (reflux having TLESR character occurring within } 10 \text { s after panesoph- } \\
\text { ageal secondary peristalsis) } \\
\text { Partial esophageal secondary peristalsis associated reflux (reflux having TLESR character occurring within } 10 \text { s after the } \\
\text { non-swallowing partial esophageal activity) } \\
\text { TLESR-reflux associated with a temporary decrease in LES tone below } 5 \text { mmHg, without association with dry swallow, } \\
\text { esophageal secondary peristalsis or cough) } \\
\text { Cough associated reflux (reflux within } 30 \text { s of cough episode/MV interference) } \\
\text { Absence of the LES tone (reflux at low LES tone below } 5 \text { mmHg, without an association with esophageal contraction or } \\
\text { cough) } \\
\text { Panesophageal secondary peristalsis, partial esophageal secondary peristalsis in the close post-refulx period (within } 10 \text { s of } \\
\text { reflux) } \\
\text { Cough } \\
\text { Agitation }\end{array}$ \\
\hline
\end{tabular}

HRM high-resolution manometry, LES lower esophageal sphincter, EGJ esophagogastric junction, TLESR transient lower esophageal sphincter relaxation, MV mechanical ventilation

a Measured 3 times in each study hour and expressed as the median for a particular study period 


\section{Statistical analysis}

Data were presented as median (interquartile range, IQR) or number (percentage) unless otherwise indicated. Data from the first $2 \mathrm{~h}$ of the study were used to analyze the key features of esophageal motility functions in critically ill patients and to compare those features and the occurrence of reflux according to LGV or HGV status. The metoclopramide administration was started after the first $2 \mathrm{~h}$ of the study, and data from the following $3 \mathrm{~h}$ were used to perform a comparison of the parameters before and after the metoclopramide administration. The Mann-Whitney $U$ test was used to compare two independent groups. Categorical data were compared by Fisher's exact test. Differences were considered statistically significant at $p$ values of $<0.05$.

\section{Results}

Demographic and clinical characteristics are presented in Table 2 . The main diagnoses were septic shock (5 patients in the LGV and 7 patients in the HGV group), COPD exacerbation (2 patients in the LGV group), cardiogenic shock (1 patient in the LGV group), and aspiration pneumonia (1 patient in the HGV group). Major pathological motility patterns were observed in all patients (Table 3 ). Esophageal motility abnormalities included both disturbances of contraction vigor, contraction and pressurization patterns and EGJ functions.

\section{Esophageal contraction vigor}

The distal contractile integral (DCI) values, which reflect contraction vigor, were significantly higher in the patients than normally seen in healthy volunteers [8], which suggested that hypercontractile esophagus was common. In addition, $44 \%$ of the critically ill patients exhibited extreme contraction vigor, based on DCI values of $>8000 \mathrm{mmHg}-\mathrm{cm}$-s for $>20 \%$ of esophageal events.

\section{Esophageal contraction pattern}

Contraction pattern characterizes esophageal peristaltic integrity, i.e., if the peristaltic activity is intact, failed,

Table 2 Demographic and clinical data of critically ill patients

\begin{tabular}{|c|c|c|c|}
\hline Variable (unit) & $\begin{array}{l}\text { Total } \\
n=16\end{array}$ & $\begin{array}{l}\text { LGV group } \\
n=8\end{array}$ & $\begin{array}{l}\text { HGV group } \\
n=8\end{array}$ \\
\hline Age (years) & $58(51-71)$ & $68(52-76)$ & $54(51-64)$ \\
\hline Body mass index & $29(25-34)$ & $32(24-33)$ & $27(25-35)$ \\
\hline Sex-men (\%) & 44 & 13 & 75 \\
\hline Interval from admission to study (days) & $5(3-5)$ & $4(3-5)$ & $5(5-5)$ \\
\hline Interval from MV start to study (days) & $4.5(3-5)$ & $3.5(3-5,3)$ & $5(4-5)$ \\
\hline APACHE II score & $35(23-39)$ & $35(24-39)$ & $33(21-39)$ \\
\hline SOFA score on the day of the study & $11(8-14)$ & $10(7-11)$ & $14(11-15)$ \\
\hline Number of days in the ICU (days) & $11(14-19)$ & $13(11-19)$ & $14(12-18)$ \\
\hline Duration of hospitalization (days) & $26(16-27)$ & $24(17-29)$ & $26(16-27)$ \\
\hline ICU mortality (\%) & 25 & 25 & 25 \\
\hline Hospitalization mortality (\%) & 44 & 50 & 38 \\
\hline GRV $24 \mathrm{~h}$ before study (mL) & $345(28-630)$ & $25(8-68)$ & $630(627-985)$ \\
\hline GRV single measurement during the study $(\mathrm{mL})$ & $30(18-90)$ & $15(0-20)$ & $90(88-200)$ \\
\hline Mean arterial pressure $(\mathrm{mmHg})$ & $92(85-100)$ & $94(88-99)$ & $90(85-100)$ \\
\hline Heart rate (beats/minute) & $84(74-104)$ & $93(79-103)$ & $77(71-100)$ \\
\hline Intraabdominal pressure $(\mathrm{mmHg})$ & $10(7-17)$ & $15,5(13-18)$ & $7(7-10)$ \\
\hline Body temperature $\left({ }^{\circ} \mathrm{C}\right)$ & $37(36-37)$ & $37(36-37)$ & $36(36-37)$ \\
\hline Number of clinical interferences & $1(0-3)$ & $2(1-3)$ & $1(0-2)$ \\
\hline Noradrenalin use during study (\%) & 31 & 25 & 38 \\
\hline Betablockers use during study (\%) & 6 & 13 & 0 \\
\hline Propofol use during study (\%) & 31 & 13 & 50 \\
\hline Sufentanil use during study (\%) & 56 & 38 & 75 \\
\hline Blood glucose (mmol/L) & $10(9-13)$ & $10(9-14)$ & $11(10-12)$ \\
\hline Arterial lactate (mmol/L) & $1,3(0,8-1,7)$ & $1,7(1,4-2)$ & $0,8(0,8-1,3)$ \\
\hline Hemoglobin (g/L) & $102(93-110)$ & $104(98-112)$ & $98(93-103)$ \\
\hline C-reactive protein (mg/L) & $72(44-176)$ & $68(17-191)$ & $72(70-176)$ \\
\hline
\end{tabular}

All values shown are median and interquartile range or percentage

LGV low gastric volumes, $H G V$ high gastric volumes, $M V$ mechanical ventilation, GRV gastric residual volume, ICU intensive care unit, LES lower esophageal sphincter 
Table 3 High-resolution manometry characteristics of critically ill patients

\begin{tabular}{|c|c|c|}
\hline Variable (unit) & $\begin{array}{l}\text { Critically ill patients } \\
n=16\end{array}$ & $\begin{array}{l}\text { Normal range for } 5 \mathrm{~mL} \text { wet } \\
\text { swallows (ref. } 8 \text { and 9) }\end{array}$ \\
\hline \multicolumn{3}{|l|}{ Dynamic (swallow) esophageal parameters } \\
\hline Distal contractile integral (mmHg cm s) & $3852(1700-7730)$ & $>450$ and $<20 \%$ more than 8000 \\
\hline Failed esophageal peristalsis ( $\%$, median/IQR) & $73(54-89)$ & $<20$ \\
\hline Panesophageal pressurization (\% median/IQR) & $64(48-79)$ & $<20$ \\
\hline Double-peaked waves (\% median/IQR) & $30(0-50)$ & $\leq 15$ \\
\hline Premature contraction (\% median/IQR) & $20(2-32)$ & $<20$ \\
\hline Rapid contraction (\% median/IQR) & $5(0-12)$ & $<20$ \\
\hline \multicolumn{3}{|l|}{ Dynamic (swallow) EGJ parameters } \\
\hline Integrated relaxation pressure ( $\mathrm{mmHg}$, median/IQR) & $16(6-21)$ & $<15$ \\
\hline Intrabolus pressure (mmHg, median/IQR) & $23(17-28)$ & $<17$ \\
\hline \multicolumn{3}{|l|}{ Static (rest) EGJ parameters } \\
\hline LES tone (mmHg, median/IQR) & $18(9-26)$ & $13-43$ \\
\hline EGJ-Cl (mmHg cm, median/IQR) & $40(28-60)$ & $25-55$ \\
\hline Inspiration EGJ pressure (mmHg, median/IQR) & $36(29-42)$ & $29-43$ \\
\hline Expiration EGJ pressure (mmHg, median/IQR) & $24(19-33)$ & $9-20$ \\
\hline Hiatal hernia presence (\%) & 19 & - \\
\hline
\end{tabular}

Normative data from healthy volunteers (ref. 8 and 9) are derived from measurements during water-swallowed induced esophageal contraction, whereas dry swallows or spontaneous contractions are analyzed in critically ill patients. Since quantitative differences in peristaltic variables exist between peristalsis associated with wet versus dry swallows, caution is needed when comparing them directly

LES lower esophageal sphincter, EGJ esophagogastric junction, EGJ-Cl esophagogastric junction contractile integral

or associated with peristaltic breaks. Despite the predominance of a hypercontractile pattern, simultaneously failed peristalsis (a propulsive contraction with a $\mathrm{DCI}<100 \mathrm{mmHg}-\mathrm{s}-\mathrm{cm}$ ) was observed for $73 \%$ (IQR 54-89\%) of the esophageal events in critically ill patients, which suggested an ineffective propulsive force. Significant irregularities in the contraction pattern were also observed, including double-peaked waves (30\%, IQR $0-50 \%)$ and premature spastic contractions (20\%, IQR $2-32 \%)$.

\section{Esophageal pressurization pattern}

Major abnormalities were detected in the pressurization patterns, with the most common being panesophageal pressurization (64\%, IQR 48-79\%). This pattern involves impaired integrity of the contraction (achalasia type II phenotype), which includes pressurization of the entire esophagus from the upper sphincter to the esophagogastric junction (EGJ).

\section{EGJ functions}

Several dynamic and static parameters were evaluated to characterize EGJ function (Table 1). Among these parameters, $50 \%$ of patients had an increased integrated relaxation pressure $(>15 \mathrm{mmHg})$ and $63 \%$ of patients had an intrabolus pressure of $>20 \mathrm{mmHg}$, which both reflect EGJ outflow obstruction during esophageal contraction. A novel static parameter for evaluating the rest
LES barrier function (the EGJ-CI parameter) [9] was decreased $(<13 \mathrm{mmHg} \mathrm{cm})$ in only 1 patient (hypocontractile type) and was increased (>55 $\mathrm{mmHg} \mathrm{cm}$ ) in $31 \%$ of patients. Representative examples of the HRIM findings are shown in Fig. 2.

\section{Comparison of LGV and HGV groups}

When we compared the manometric parameters according to the feeding tolerance, the LGV group commonly had the hypercontractile pattern with panesophageal pressurization, while the HGV group had the normocontractile pattern with failed peristalsis (Table 4, Additional file 2). Relative to the HGV group, the LGV group generally had more esophageal events, which often involved premature peristalses and rapid contractions, and also had more double-peaked waves. Moreover, the LES had a higher tone in the LGV group and significantly higher integrated relaxation pressure, which suggested EGJ outflow obstruction. In contrast, only patients in the HGV group (31\%) had a LES with a lower tone $(<13 \mathrm{mmHg})$.

\section{Reflux testing in critically ill patients}

Table 5 shows the impedance testing results. During the 5-h study period, a total of 195 reflux episodes were observed among all patients (11; IQR: 4-18) and reflux prevalence was $81 \%$ during the first $2 \mathrm{~h}$ of the study (i.e., at least 1 reflux episode before the metoclopramide administration). There was substantial heterogeneity 


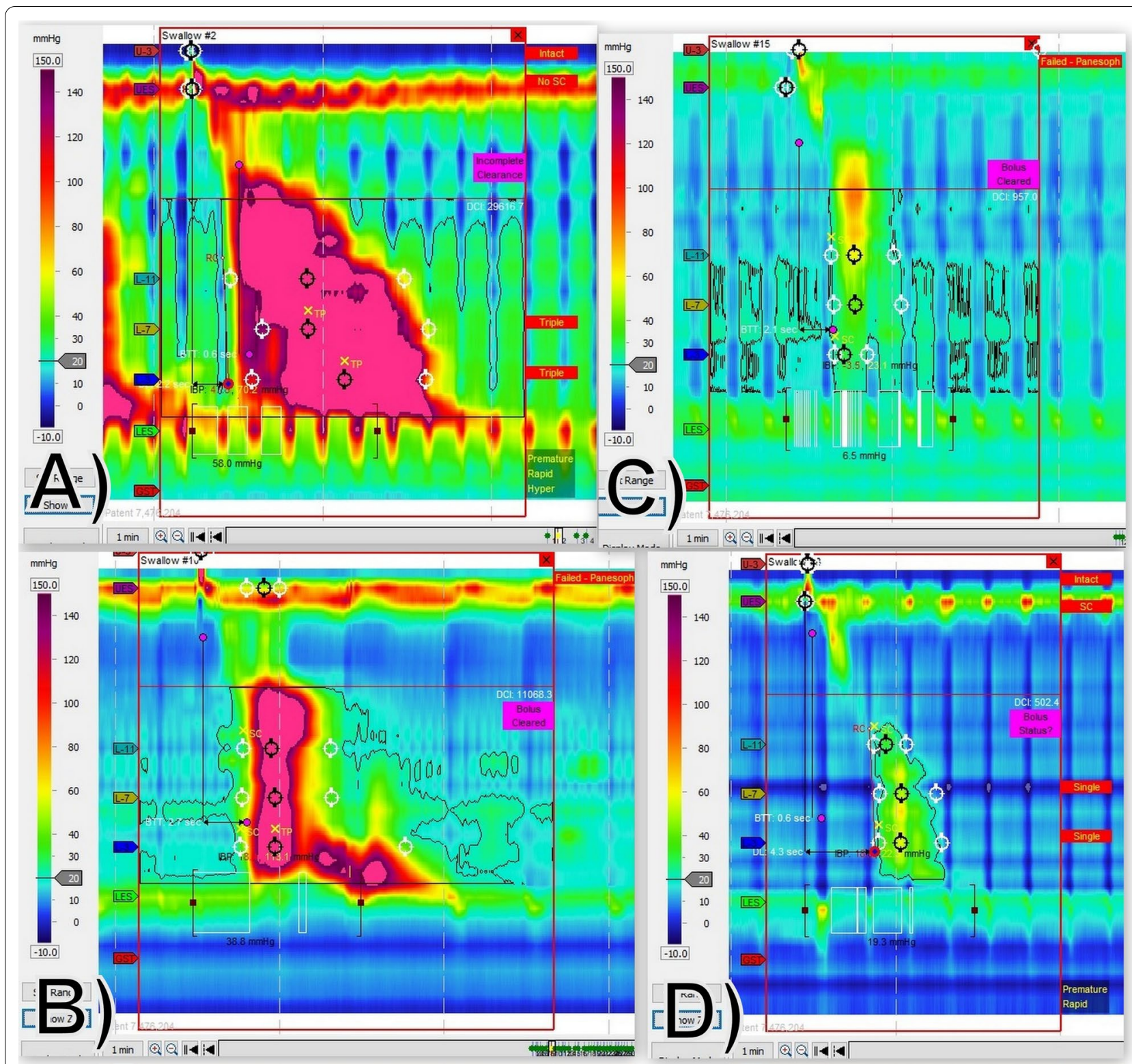

Fig. 2 Most common esophageal motor pattern in ventilated critically ill patients. a Swallow followed by hypercontractile, spastic contraction, and poor LES relaxation (distal contractile integral $29,617 \mathrm{mmHg} \mathrm{cm} \mathrm{s}$, distal latency $2.2 \mathrm{~s}$, integrated relaxation pressure of LES $58 \mathrm{mmHg}$ ). b Swallow followed by hypercontractile panesophageal pressurization and poor LES relaxation (distal contractile integral 11,068 $\mathrm{mmHg} \mathrm{cm} \mathrm{s}$, integrated relaxation pressure of LES $39 \mathrm{mmHg}$ ). c Swallow followed by normocontractile panesophageal pressurization and normal LES relaxation (distal contractile integral $957 \mathrm{mmHg} \mathrm{cm} \mathrm{s}$, integrated relaxation pressure of LES $6.5 \mathrm{mmHg}$ ). $\mathbf{d}$ Swallow followed by spastic contraction with normal contraction vigor and poor LES relaxation (distal contractile integral $502 \mathrm{mmHg} \mathrm{cm} \mathrm{s,} \mathrm{distal} \mathrm{latency} 4.3 \mathrm{~s}$, integrated relaxation pressure of LES $19 \mathrm{mmHg}$ ). LES lower esophageal sphincter

as the number per patient ranged between 0 and 34 (Additional file 3). Thirty-eight episodes (19.5\%) were proximal (i.e., reflux reaching the border of the upper esophageal sphincter), with most being mixed (19 episodes, $50 \%$ ) or liquid (17 episodes, $45 \%$ ) and only 2 episodes being gaseous. Reflux was most commonly associated with transient lower esophageal sphincter relaxation (TLESR, defined as LES relaxations in the absence of swallow; 133 out of 195 episodes, 68\%). In addition, TLESR was preceded by panesophageal secondary peristalsis in 90 of all reflux episodes (46\%). By contrast, reflux associated with absence of LES tone was less common (35 episodes, 18\%). Similarly, 12 episodes (6\%) were associated with cough, ventilator 
interference, or agitation. Representative examples of the most common reflux types based on the HRIM images are shown in Fig. 3. Interestingly, the total number of reflux episodes was noticeably higher in the LGV group than in the HGV group (Table 5). Moreover, two different esophageal motility patterns were associated with the reflux, as most episodes in the LGV group (76/121 episodes, 63\%) were associated with TLESR preceded by panesophageal secondary peristalsis, while events, especially in the LGV group, but did not influence panesophageal pressurization or premature contraction. Similarly, there was a tendency toward reduced contraction vigor, based on the DCI value, which was predominantly observed in the LGV group. Nevertheless, metoclopramide appeared to exert different effects on the EGJ function and LES barrier function in the two groups. In the LGV group, metoclopramide significantly improved LES relaxation during esophageal activ-

Table 4 Characteristics of HRIM parameters according to feeding tolerance

\begin{tabular}{lll}
\hline Variable (unit) & $\begin{array}{l}\text { LGV group } \\
\mathbf{n = 8}\end{array}$ & $\begin{array}{l}\text { HGV group } \\
\mathbf{n} \mathbf{8}\end{array}$ \\
\hline Number of panesophageal events /h & $17(11-26)$ & $6(4-8)^{*}$ \\
Distal contractile integral (mmHg cm s, median/IQR) & $7661(1580-11,908)$ & $3111(1700-5068)$ \\
Failed esophageal peristalsis (\%, median/IQR) & $62(50-73)$ & $85(69-98)$ \\
Panesophageal pressurization (\%, median/IQR) & $62(50-73)$ & $69(43-83)$ \\
Double-peaked waves (\%, median/IQR) & $48(43-51)$ & $0(0-5)^{*}$ \\
Premature contraction (\%,median/IQR) & $31(25-37)$ & $2(1-19)^{*}$ \\
Rapid contraction (\%, median/IQR) & $12(11-22)$ & $0(0-0)^{*}$ \\
Integrated relaxation pressure (mmHg, median/IQR) & $20(16-28)$ & $6(6-16)$ \\
Intrabolus pressure (mmHg, median/IQR) & $19(16-27)$ & $25(19-30)$ \\
LES tone (mmHg, median/IQR) & $25(19-31)$ & $9(8-16)^{*}$ \\
EGJ-CI (mmHg cm, median/IQR) & $53(40-60)$ & $30(20-50)$ \\
Inspiration EGJ pressure (mmHg, median/IQR) & $40(35-48)$ & $34(28-36)$ \\
Expiration EGJ pressure (mmHg, median/IQR) & $30(22-35)$ & $20(19-25)$ \\
Hiatal hernia presence (\%) & 13 & 25
\end{tabular}

LGV low gastric volumes, $H G V$ high gastric volumes, LES lower esophageal sphincter, $E G J$-Cl esophagogastric junction contractile integral

*LGV versus HGV, Man Whitney test, $p<0.05$

Table 5 Impedance analysis of critically ill patients in the LGV and HGV group

\begin{tabular}{llll}
\hline Reflux type (number of all refluxes in the group) & $\begin{array}{l}\text { Total } \\
\mathbf{n = 1 6}\end{array}$ & $\begin{array}{l}\text { LGV group } \\
\mathbf{n = 8}\end{array}$ & $\begin{array}{l}\mathbf{n = 8} \\
\text { Swallow (primary peristalsis) associated reflux }\end{array}$ \\
Reflux in TLESR with preceding panesophageal secondary peristalsis & 21 & 16 & 5 \\
Reflux in TLESR with preceding partial esophageal secondary peristalsis & 90 & 76 & 14 \\
Reflux in TLESR without preceding esophageal secondary peristalsis & 25 & 12 & 7 \\
Absence of the LES tone & 35 & 11 & 34 \\
Cough associated reflux & 6 & 5 & 1 \\
Total & 195 & 121 & 74 \\
\hline
\end{tabular}

LGV low gastric volumes, $H G V$ high gastric volumes, LES lower esophageal sphincter, TLESR transient lower esophageal sphincter relaxation

episodes were commonly associated with absence of LES tone in the HGV group (34/74 episodes, 46\%).

\section{Effects of metoclopramide}

In critically ill patients (Table 6), metoclopramide significantly decreased the total number of esophageal ity (based on a reduced integrated relaxation pressure value), but impaired the resting LES barrier function (based on a decreased EGJ-CI value). In contrast, metoclopramide in the HGV group improved the vigor of the distal esophageal contraction (based on inspiration and expiration EGJ pressures) and thereby improved the EGJ 
(See figure on next page.)

Fig. 3 High-resolution impedance manometry picture of most frequent reflux types in critically ill patients. On the right high-resolution impedance manometry flowchart, on the left impedance curves for the same time period. a proximal reflux associated with transient lower esophageal sphincter relaxation (TLESR) with preceding panesophageal secondary peristalsis and terminated by secondary peristalsis. $\mathbf{b}$ Distal reflux in the absence of lower esophageal sphincter tone. $\mathbf{c}$ Distal reflux associated with dry swallow and terminated by secondary peristalsis. $\mathbf{d}$ Distal reflux associated with TLESR without preceding secondary peristalsis terminated by secondary peristalsis

barrier function. Nevertheless, metoclopramide failed to change the number reflux episodes in either group.

\section{Discussion}

This is the first study to use HRIM to characterize esophageal motor activity, reflux mechanisms, and response to metoclopramide in mechanically ventilated critically ill patients during their early recovery phase. The most common patterns were hypercontractility with premature contractions, ineffective propulsive force, and panesophageal pressurization. Gastroesophageal reflux predominantly occurred due to TLESR that was often preceded by panesophageal secondary peristalsis, and reflux was only associated with the absence of LES tone and episodes of straining in a minority of patients. In addition, although all patients had major abnormalities in their contraction vigor and contraction patterns, their characteristics varied according to gastric nutritional tolerance, which is a surrogate parameter for gastrointestinal dysfunction. For example, the LGV group was more likely to have the hypercontractile pattern with panesophageal pressurization, EGJ outflow obstruction, and more frequent reflux. In contrast, delayed gastric emptying was associated with the normal contraction vigor, failed peristalsis, reduced LES tone, and paradoxically fewer reflux episodes. In addition, metoclopramide had opposite effects on the EGJ barrier function in the LGV and HGV groups, but failed to alter the number of reflux episodes in either group.

Very few studies have evaluated quantitative and qualitative physiological parameters of esophageal motility in critically ill $[2,3,5]$, and none of those studies have used HRIM in mechanically ventilated patients. The introduction of HRIM in the field of gastroenterology led to the development of novel objective metrics and patterns for describing esophageal motility functions [9]. Hypercontractility with panesophageal pressurization was the most common motor abnormality in our patients, although we observed a very complex spectrum of altered esophageal physiologies. In this context, our study is markedly different from the study performed by Kölbel et al., who used conventional manometry and reported that considerable esophageal hyporeactivity was characterized by reduced propulsive motility, in terms of both the frequency and amplitude of contractions [2]. The difference between their findings and ours might be related to the more intensive analgosedation protocol that they used. Our findings also provide a strong physiological explanation for the negative results of a recent study, which revealed that esophageal electrical stimulation failed to prevent regurgitation and enhance feeding [10].

Another major feature of this study is the evaluation of esophageal physiology in two different gastric motility states. We observed that the LGV group had significantly more esophageal activities than the HGV group, which were associated with greater contraction vigor, more double-peaked waves, and premature and rapid contractions. These factors all reflect spastic peristalsis. Interestingly, a substantial proportion of patients exhibited extremely vigorous peristalsis, which is a pattern that resembles jackhammer (hypercontractile) esophagus [8]. The hyperreactive pattern that was more common in the LGV group was also associated with signs of EGJ outflow obstruction, while ineffective esophageal motility with reduced LES tone was only observed in the HGV group. These intergroup differences may have several explanations. First, the HGV group tended to have higher SOFA scores on the day of measurement and more severe acute kidney injury, which both suggests more severe illness. Furthermore, more frequent use of analgosedation could negatively affect gastrointestinal motility and enteral feeding tolerance in the HGV group [11], whereas the less frequent use of propofol and sufentanil could make the LGV patients more sensitive to irritation caused by the endotracheal and/or nasogastric tubes. Nevertheless, that reasoning is speculative, as the analgosedation was titrated to target the same Richmond Agitation Sedation Score in both groups. Our results may also reflect a physiological connection between esophageal and gastric motility patterns. Indeed, the greater motility in the UGIT of patients in the LGV group might be associated with very good gastric feeding tolerance. However, it was also accompanied by esophageal hypercontractility and EGJ outflow obstruction. The clinical significance of this pattern remains unclear and is it not necessarily indicative of an underlying pathology.

Abnormal esophagus motility disorders in mechanically ventilated patients could be associated with significant clinical consequences, which are related to gastroesophageal reflux and pulmonary aspiration [1]. In 


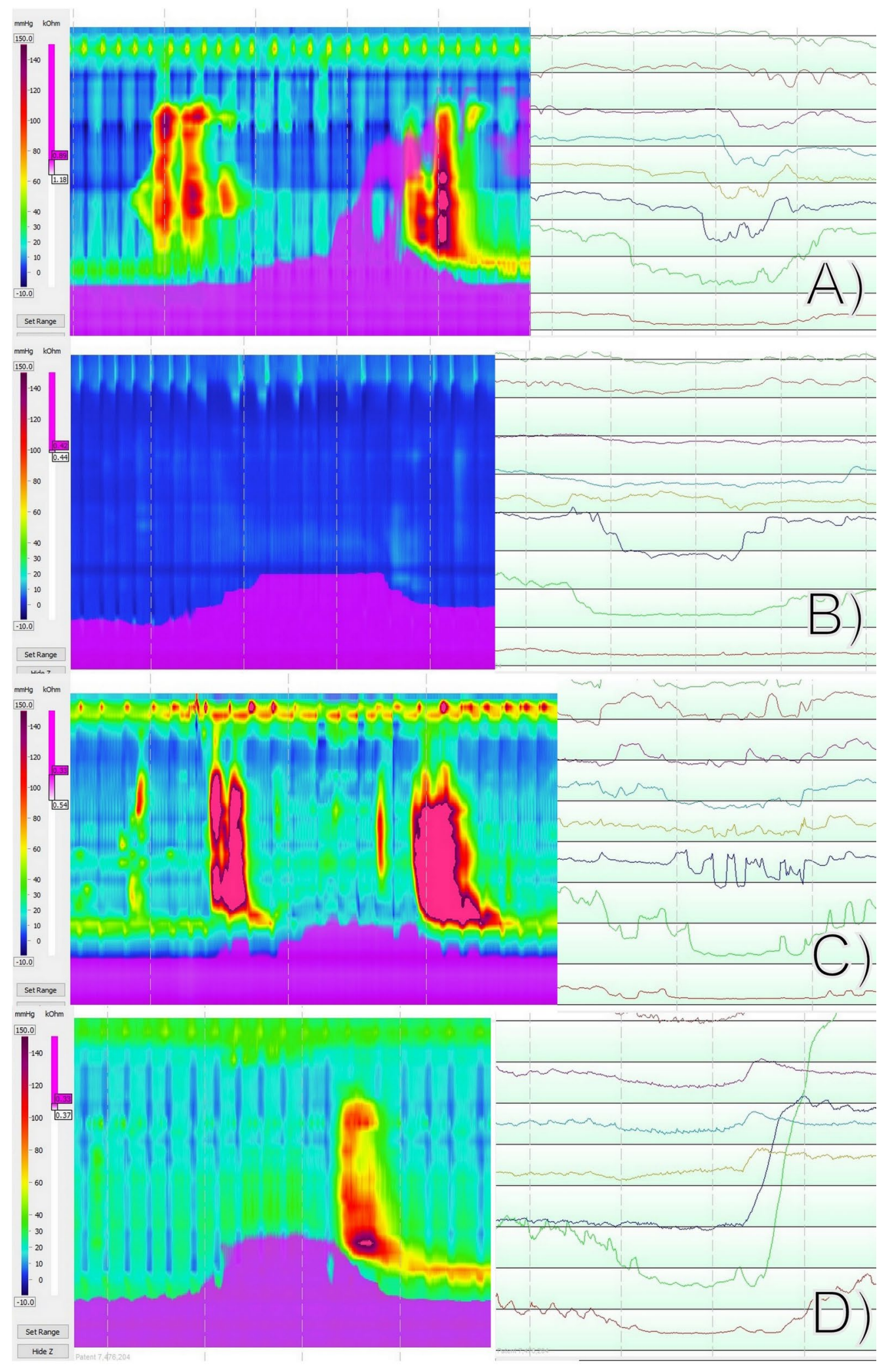


Table 6 HRIM analysis before and after metoclopramide administration in critically ill patients

\begin{tabular}{|c|c|c|c|c|c|c|}
\hline \multirow[t]{2}{*}{ Variable (unit) } & \multicolumn{3}{|c|}{ Before metoclopramide } & \multicolumn{3}{|c|}{ After metoclopramide } \\
\hline & Total & LGV & HGV & Total & LGV & HGV \\
\hline GRV during the study ( $\mathrm{mL})$ & $30(18-90)$ & $15(0-20)$ & $90(88-200)$ & $15(10-160)$ & $10(0-10)$ & $160(88-213)$ \\
\hline $\begin{array}{l}\text { Number of esophageal activi- } \\
\text { ties /hour }\end{array}$ & $10(6-17)$ & $17(11-26)$ & $6(4-8)$ & $7(5-13)^{*}$ & $11(7-15)^{*}$ & $5(4-9)$ \\
\hline $\begin{array}{l}\text { Distal contractile integral } \\
(\mathrm{mmHg} \mathrm{cm} \mathrm{s})\end{array}$ & 3852 (1700-7730) & $7661(1580-11,908)$ & $3111(1700-5068)$ & 3004 (1900-8091) & $5096(1699-8916)$ & $2805(2081-4488)$ \\
\hline $\begin{array}{l}\text { Failed esophageal peristalsis } \\
\text { (median of \%) }\end{array}$ & $73(54-89)$ & $62(50-73)$ & 85 (69-98) & $80(58-100)$ & $68(53-85)$ & $94(69-100)$ \\
\hline $\begin{array}{l}\text { Panesophageal pressurization } \\
\text { (median of \%) }\end{array}$ & $64(48-79)$ & $62(50-73)$ & $69(43-83)$ & $74(45-88)$ & $68(53-85)$ & $80(45-90)$ \\
\hline $\begin{array}{l}\text { Double-peaked waves } \\
\text { (median of \%) }\end{array}$ & $30(0-50)$ & $48(43-51)$ & $0(0-5)$ & $0(0-25)^{* *}$ & $25(8-35)^{*}$ & $0(0-0)$ \\
\hline $\begin{array}{l}\text { Premature contraction } \\
\text { (median of \%) }\end{array}$ & $20(2-32)$ & $31(25-37)$ & $2(1-19)$ & $10(0-41)$ & $33(10-48)$ & $0(0-3)$ \\
\hline $\begin{array}{l}\text { Integrated relaxation pressure } \\
(\mathrm{mmHg})\end{array}$ & $16(6-21)$ & $20(16-28)$ & $6(6-16)$ & $14(7-19)$ & $17(14-24)^{*}$ & $7(6-10)$ \\
\hline Intrabolus pressure $(\mathrm{mmHg})$ & $23(17-28)$ & $19(16-27)$ & $25(19-30)$ & $24(20-27)$ & $24(21-26)$ & $24(19-29)$ \\
\hline LES tone $(\mathrm{mmHg})$ & $18(9-26)$ & $25(19-31)$ & $9(8-16)$ & $18(12-27)$ & $23(18-30)$ & $12(9-20)$ \\
\hline $\mathrm{EGJ}-\mathrm{Cl}(\mathrm{mmHg} \mathrm{cm})$ & $40(28-60)$ & $53(40-60)$ & $30(20-50)$ & $33(2-53)$ & $43(30-53)^{*}$ & $30(26-44)$ \\
\hline $\begin{array}{l}\text { Inspiration EGJ pressure } \\
(\mathrm{mmHg})\end{array}$ & $36(29-42)$ & $40(35-48)$ & $34(28-36)$ & $42(30-44)$ & $40(34-45)$ & $42(27-44)^{*}$ \\
\hline $\begin{array}{l}\text { Expiration EGJ pressure } \\
(\mathrm{mmHg})\end{array}$ & $24(19-33)$ & $30(22-35)$ & $20(19-25)$ & $25(23-32)$ & $27(24-32)$ & $23(21-29)^{*}$ \\
\hline $\begin{array}{l}\text { Number of reflux episodes/ } \\
\text { patient/hour }\end{array}$ & $1.8(0.5-3.5)$ & $3.3(2-3.6)$ & $0.8(0.4-1.5)$ & $2.4(0.9-3.6)$ & $2.9(2.3-3.7)$ & $1.1(0.5-2.6)$ \\
\hline
\end{tabular}

All values shown are median and interquartile range

GRV gastric residual volume, LES lower esophageal sphincter, EGJ-Cl esophagogastric junction contractile integral

*The Mann-Whitney $U$ test, $p<0,05$

this context, low LES pressure and weak or even absent esophageal peristalsis has been traditionally considered crucial for the development of gastroesophageal reflux in critically ill patients [2]. For example, Nind et al. reported that low or absent LES pressure and inadequate esophageal propulsive forces led to poor acid clearance, which was considered the most common mechanism associated with reflux [3]. However, our data suggest that maintaining rest LES tone may not be essential for preventing reflux, as almost $70 \%$ of the reflux episodes we observed occurred due to TLESR. Although TLESR may be a normal physiological motor event in healthy subjects [12], previous studies have proven that TLESR plays a crucial role in the occurrence of gastroesophageal reflux disease [13]. It appears that the major mechanisms of reflux in our cohort of patients recovering from critical illness and receiving minimal sedation are similar to non-ventilated patients. By contrast, a notable feature of esophageal activity that often preceded TLESR was panesophageal secondary peristalsis, an abnormality never seen in healthy subjects [12]. It remains unclear, whether this secondary peristalsis is itself a trigger of TLESR. Of note, the absence of LES tone was associated with only a small minority of reflux episodes (18\%), and this situation was only observed in patients with HGV. Furthermore, high residual gastric volumes are commonly thought to increase the risk of gastroesophageal reflux [14]. Interestingly, patients in the LGV group had substantially better gastric emptying but also more reflux episodes than patients in the HGV group. Our observations are corroborated by the findings reported by McClave et al., who were unable to identify a threshold for residual gastric volumes that was associated with increased risks of aspiration and pneumonia [15]. Thus, it appears that reflux disease cannot be excluded based on the presence of well-preserved gastric emptying, maintained LES tone, and well-preserved EGJ barrier function in critically ill patients.

Metoclopramide is frequently used to promote motility in the UGIT. However, its beneficial effects remain unclear in critically ill patients [16], and we are not aware of any comprehensive studies regarding the effects of metoclopramide on esophageal physiology and EGJ function. We observed that metoclopramide did not substantially reduce the number of reflux episodes in either group of critically ill patients. In addition, its effects on 
esophageal functions are noticeably different in the healthy volunteers, where it markedly increases the contraction vigor [15]. Across the observed spectrum of abnormal motility patterns, metoclopramide also paradoxically decreased the number of esophageal events and even tended to weaken the strength of contractions, especially in the LGV group. The mechanisms underlying these unexpected effects remain unclear. In addition, metoclopramide did not substantially influence failed esophageal peristalsis, esophageal pressurization, or EGJ-related parameters. Thus, HRIM does not appear to be able to clinically identify critically ill patients who are likely to benefit from prokinetic stimulation.

This study has several limitations. First, the small sample size may preclude generalization of the results because of selection bias, although this study was only designed as an exploratory physiological study. Focusing on population with "normal" and "delayed" gastric emptying, we studied only patients with two pre-defined, well-separated thresholds for gastric residuals. Hence, the results might not be valid for a wider spectrum of gastric feeding tolerance. Likewise, the observed relationships between reflux and different esophageal patterns should be interpreted with caution as they may be influenced by a correlation within a small number of patients. Second, critical illness is a dynamic process and analyses from a single timepoint only provide a limited perspective regarding these patients. Thus, we suggest that further studies are needed to assess the dynamic long-term implications of our HRIM findings. Third, the definition of abnormalities described in the Chicago classification is based on the analysis of ten 5-ml swallows in patients suffering from dysphagia and/or chest pain and therefore may not necessarily apply to the manometric analysis in ICU patients, in whom dry swallows or spontaneous secondary peristalsis were studied. Finally, all our critically ill patients received anti-ulcer prophylaxis and $\mathrm{pH}$ monitoring was not performed for various reasons, including the technical complexity of introducing a $\mathrm{pH}$-meter catheter to the nasogastric tube and HRIM catheter.

\section{Conclusions}

In conclusion, this study revealed that HRIM was useful for clarifying the complex esophageal physiology in critically ill patients. HRIM testing in critically ill patients has been found safe and feasible. The results revealed marked heterogeneity in the esophageal motor dysfunctions, as well as links between gastric emptying, esophageal motor patterns, and gastroesophageal reflux. Our study also provides valuable insights into the physiological effects of metoclopramide in this population. Nevertheless, additional studies are needed to better understand the clinical relevance and implications of our findings.

\section{Supplementary information}

The online version contains supplementary material available at https://doi. org/10.1186/s13054-021-03479-8.

Additional file 1. Study protocol and high-resolution impedance manometry record analysis details.

Additional file 2 . High-resolution motility data in critically ill patients. Additional file 3. Number of reflux episodes for the entire of recording period.

\section{Abbreviations}

DCl: Distal contractile integral; EGJ: Esophagogastric junction; GRV: Gastric residual volume; HGV: High residual gastric volumes; HRIM: High-resolution impedance manometry; LES: Lower esophageal sphincter; LGV: Low residual gastric volumes; TLESR: Transient lower esophageal sphincter relaxation; UGIT: Upper gastrointestinal tract.

\section{Acknowledgements}

Not applicable.

\section{Authors' contributions}

KB designed the study, participated in the data collection and analysis, and wrote the manuscript. JK and LZ were involved in the data collection and analysis. MK performed the statistical analysis and wrote part of the manuscript. JK performed the second independent data analysis and wrote part of the manuscript. MM obtained research funding, supervised and coordinated the study, and finalized the manuscript. All authors read and approved the final manuscript.

\section{Funding}

This study was supported by the Ministry of Health, Czech Republic - Conceptual Development of Research Organization [Faculty Hospital in Pilsen-FNPI, 00669806], by the Charles University Research Fund [project no. Q39], and by a grant for "Fighting Infectious Diseases" awarded by the MEYS CR and financed by the EFRR project [CZ.02.1.01/0.0/0.0/16_019/0000787]. The study sponsor and funders have no impact on study design, collection, management, analysis, interpretation of data and writing of the report. The sponsor support submitting the report for publication without any ultimate authority over any of these activities.

\section{Availability of data and materials}

The data that support the findings of this study will be available from the first author upon reasonable request (email: balihar@fnplzen.cz). Supporting data will be made available to Editorial Board Members and referees at the time of submission for the purposes of evaluating the manuscript and directly upon request to any reader on and after the publication date. Supporting datasets will be made available as Supplementary Information files that will be freely accessible on the journal's website upon publication.

\section{Code availability \\ License for High resolution manometry software: ManoScan ESO: NLI- HFEDCA, ManoView ESO: 21-E413-9824.}

\section{Ethics approval and consent to participate}

This study's protocol was approved by the ethics committee of Faculty hospital Pilsen Czech Republic (approval number: 230/2012). Local ethical committee FN Pilsen. Address: Edvarda Benese 13, 305 99, Pilsen, Czech Republic. Tel:/ Fax: +420 377423 275. Head of Committee: David Suchý, MD, PhD.Scientific Secretary: Assistance Professor Milan Hora, MD, PhD. Email: snebergerova@ fnplzen.cz. All subjects or their next of kin provided informed consent for participation in this study. 


\section{Competing interests}

All the authors do not have any conflicts of interest to declare.

Received: 17 September 2020 Accepted: 25 January 2021

Published online: 08 February 2021

\section{References}

1. Ladopoulos T, Giannaki M, Alexopoulou C, Proklou A, Pediaditis E, Kondili E. Gastrointestinal dysmotility in critically ill patients. Ann Gastroenterol. 2018. https://doi.org/10.20524/aog.2018.0250.

2. Kolbel CB, Rippel K, Klar H, Singer MV, Van AK, Fiedler F. Esophageal motility disorders in critically ill patients: a 24-hour manometric study. Intensive Care Med. 2000. https://doi.org/10.1007/s001340000630.

3. Nind G, Chen WH, Protheroe R, Iwakiri K, Fraser R, Young R, Chapman M, Nguyen N, Sifrim D, Rigda R, Holloway RH. Mechanisms of gastroesophageal reflux in critically ill mechanically ventilated patients. Gastroenterology. 2005. https://doi.org/10.1053/j.gastro.2004.12.034.

4. Savarino E, Marabotto E, Bodini G, Furnari M, Della CM, Ghisa M, Barberio B, Frazzoni M, De BN, Zentilin P, Pellegatta G, Tolone S, Ottonello A, Savarino $\mathrm{V}$. Advancements in the use of manometry and impedance testing for esophageal functional disorders. Expert Rev Gastroenterol Hepatol. 2019. https://doi.org/10.1080/17474124.2019.1595587.

5. Schar MS, Omari TI, Fraser RJ, Bersten AD, Bihari S. Disordered swallowing associated with prolonged oral endotracheal intubation in critical illness. Intensive Care Med. 2020. https://doi.org/10.1007/s00134-018-5181-1.

6. Persson P, Ahlstrand R, Gudmundsson M, De LA, Lundin S. Detailed measurements of oesophageal pressure during mechanical ventilation with an advanced high-resolution manometry catheter. Crit Care. 2019. https:// doi.org/10.1186/s13054-019-2484-8.

7. Ahlstrand R, Thörn S-E, Wattwil M. High-resolution solid-state manometry of the effect of rocuronium on barrierpressure. Acta Anaesthesiol Scand. 2011. https://doi.org/10.1111/j.1399-6576.2011.02517.x.

8. Kahrilas PJ, Bredenoord AJ, Fox M, Gyawali CP, Roman S, Smout AJ, Pandolfino JE, International High Resolution Manometry Working Group. The Chicago Classification of esophageal motility disorders, v3.0. Neurogastroenterol Motil. 2015. https://doi.org/10.1111/nmo.12477.

9. van Hoeij FB, Bredenoord AJ. Clinical application of esophageal highresolution manometry in the diagnosis of esophageal motility disorders. J Neurogastroenterol Motil. 2016. https://doi.org/10.5056/jnm15177.
10. Heyland DK, Marquis F, Lamontagne F, Albert M, Turgeon AF, Khwaja KA, Garland A, Hall R, Chapman MG, Kutsiogannis DJ, Martin C, Sessler DI, Day AG. Promotion of regular oesophageal motility to prevent regurgitation and enhance nutrition intake in long-stay ICU patients. A Multicenter, Phase II, Sham-Controlled, Randomized Trial: The PROPEL Study. Crit Care Med. 2020. https://doi.org/10.1097/CCM.0000000000004176.

11. Fruhwald $\mathrm{S}$, Holzer $\mathrm{P}$, Metzler $\mathrm{H}$. Intestinal motility disturbances in intensive care patients pathogenesis and clinical impact. Intensive Care Med. 2007. https://doi.org/10.1007/s00134-006-0452-7.

12. He S, Jell A, Hüser N, Kohn N, Feussner H. 24-hour monitoring of transient lower esophageal sphincter relaxation events by long-term high-resolution impedance manometry in normal volunteers: the "mirror phenomenon." Neurogastroenterol Motil. 2019. https://doi.org/10.1111/nmo.13530.

13. Schneider JH, Küper MA, Königsrainer A, Brücher BL. Transient lower esophageal sphincter relaxation and esophageal motor response. J Surg Res. 2010. https://doi.org/10.1016/j.jss.2009.02.021.

14. Westphal M. Science and fiction in critical care: established concepts with or without evidence? Crit Care. 2019. https://doi.org/10.1186/s1305 4-019-2419-4.

15. McClave SA, Lukan JK, Stefater JA, Lowen CC, Looney SW, Matheson PJ, Gleeson K, Spain DA. Poor validity of residual volumes as a marker for risk of aspiration in critically ill patients. Crit Care Med. 2005. https://doi. org/10.1097/01.ccm.0000153413.46627.3a.

16. Lewis K, Alqahtani Z, Mcintyre L, Almenawer S, Alshamsi F, Rhodes A, Evans L, Angus DC, Alhazzani W. The efficacy and safety of prokinetic agents in critically ill patients receiving enteral nutrition: a systematic review and meta-analysis of randomized trials. Crit Care. 2016. https://doi. org/10.1186/s13054-016-1441-z.

17. Mikami H, Ishimura N, Fukazawa K, Okada M, Izumi D, Shimura S, Okimoto E, Aimi M, Ishihara S, Kinoshita Y. Effects of metoclopramide on esophageal motor activity and esophagogastric junction compliance in healthy volunteers. J Neurogastroenterol Motil. 2016. https://doi.org/10.5056/ jnm15130.

\section{Publisher's Note}

Springer Nature remains neutral with regard to jurisdictional claims in published maps and institutional affiliations.
Ready to submit your research? Choose BMC and benefit from:

- fast, convenient online submission

- thorough peer review by experienced researchers in your field

- rapid publication on acceptance

- support for research data, including large and complex data types

- gold Open Access which fosters wider collaboration and increased citations

- maximum visibility for your research: over $100 \mathrm{M}$ website views per year

At BMC, research is always in progress.

Learn more biomedcentral.com/submissions 